\title{
The mediating effect of calling on the relationship between medical school students' academic burnout and empathy
}

\author{
Su Jin Chae ${ }^{1,2}$, So Mi Jeong ${ }^{2}$ and Yoon-Sok Chung ${ }^{1,3}$ \\ ${ }^{1}$ Department of Medical Humanities \& Social Medicine, ${ }^{2}$ Office of Medical Education, ${ }^{3}$ Department of Endocrinology \\ and Metabolism, Ajou University School of Medicine, Suwon, Korea
}

Purpose: This study is aimed at identifying the relationships between medical school students' academic burnout, empathy, and calling, and determining whether their calling has a mediating effect on the relationship between academic burnout and empathy. Methods: A mixed method study was conducted. One hundred twenty-seven medical students completed a survey. Scales measuring academic burnout, medical students' empathy, and calling were utilized. For statistical analysis, correlation analysis, descriptive statistics analysis, and hierarchical multiple regression analyses were conducted. For qualitative approach, eight medical students participated in a focus group interview.

Results: The study found that empathy has a statistically significant, negative correlation with academic burnout, while having a significant, positive correlation with calling. Sense of calling proved to be an effective mediator of the relationship between academic burnout and empathy.

Conclusion: This result demonstrates that calling is a key variable that mediates the relationship between medical students' academic burnout and empathy. As such, this study provides baseline data for an education that could improve medical students' empathy skills.

Key Words: Burnout, Career choice, Medical education

\section{Introduction}

The rapidly changing medical environment necessitates change in the roles played by medical doctors and the type of education provided to medical students. In relation to this, Korean and international medical experts recently specified the roles and capabilities required of doctors [1]. In particular, empathy is garnering attention as one of the core capabilities that a good doctor should have. Empathy refers to a skill entailing comprehension of others' psychological status or an emotional reaction to others' pain [2]. Empathy is an essential element in the establishment of a desirable doctor-patient relationship and increases patient satisfaction, therefore, influencing the outcomes and quality of medical services. Previous literature found that doctors with less empathy were more likely to consciously engage in medical malpractice, and tended to experience symptoms of exhaustion and stress [3,4]. These findings might also apply to medical students. According to some research medical students [5], as they receive medical training
Received: January 5, 2017 • Revised: May 30, 2017 • Accepted: June 8, 2017 Corresponding Author: Su Jin Chae (https://orcid.org/0000-0003-3060-8933)

Department of Medical Humanities \& Social Medicine, Ajou University School of Medicine, 164 World cup-ro, Yeongtong-gu, Suwon 16499, Korea

Tel: +82.31.219.4511 Fax: +82.31.219.4093 email: edujin@ajou.ac.kr
Korean J Med Educ 2017 Sep; 29(3): 165-173.

https://doi.org/10.3946/kjme.2017.62

eISSN: 2005-7288

(C) The Korean Society of Medical Education. All rights reserved. This is an open-access article distributed under the terms of the Creative Commons Attribution Non-Commercial License (http:// creativecommons.org/licenses/by-nc/3.0/), which permits unrestricted non-commercial use, distribution, and reproduction in any medium, provided the original work is properly cited. 
and get used to medical situations, tend to have lower empathic ability; moreover, those with more burnout and poorer quality of life are less empathetic. Despite the clear importance of empathy, not much empirical research has been conducted in Korea on how empathy and academic burnout are related. As such, the present study was initially aimed at identifying a mediating variable that could enhance the empathic capacity of medical students who are under extreme academic stress. The concept of a sense of calling refers to a sense of purpose that helps people feel satisfied with their own work or encourages them to make meaningful contributions to society [6]. According to existing literature [7], sense of calling is one of the variables that could lower the negative effects of job stress. A recent study by Peterson et al. [8] found calling to moderately correlate with work zest and life satisfaction and strongly correlate with work satisfaction. While it is not yet a familiar concept to Koreans in the medical education field, researchers are actively examining individuals' happiness or wellbeing, given the considerable attention that positive psychology has attracted recently [9]. Those with a strong sense of calling are not only content with their occupations, but are also resilient enough to continue working, even when faced with hardships [10]. A sense of calling has been proven to prevent occupational stress, depression, and psychological burnout [11]. Moreover, people with a sense of calling tend to attach meaning to their work, feeling less stressed and more satisfied with what they do for a living, instead of regarding it as a tool that does [10]. These research findings indicate that a sense of calling could be an essential factor affecting the association between medical students' empathy and academic burnout.

In this regard, this study is aimed at examining how medical students' empathic ability, academic burnout, and sense of calling are related to one another, and at investigating whether sense of calling has a mediating effect on the relationship between empathy and academic burnout. The results of this study are expected to help build a database for a system that could reduce academic burnout among medical students.

\section{Methods}

\section{Participants}

The present study was based on a survey distributed to 171 first- to fourth-year medical students attending Ajou University School of Medicine, Korea. Of all of the collected data, the data of 127 students who had provided valid responses on the survey were analyzed. Table 1 shows the distribution of the study subjects according to study year and gender. The focus group interview (FGI) was conducted in eight medical students after informed consent was obtained, and consisted of four females and four males, who were two class representatives from

Table 1. Distribution of Study Subjects

\begin{tabular}{|c|c|c|c|}
\hline \multirow{2}{*}{ School year } & \multicolumn{2}{|c|}{ Gender } & \multirow{2}{*}{ Total $|\%|$} \\
\hline & Male $(\%)$ & Female $(\%)$ & \\
\hline M1 & $19(28.4)$ & $16(26.7)$ & $35(27.6)$ \\
\hline M2 & 20 (29.9) & 19 (31.7) & 39 (30.7) \\
\hline M3 & 17 (25.3) & $17(28.3)$ & 34 (26.8) \\
\hline M4 & $11(16.4)$ & 8 (13.3) & $19(14.9)$ \\
\hline Total & 67 (100.0) & 60 (100.0) & $127(100.0)$ \\
\hline
\end{tabular}


each academic year.

\section{Measures}

\section{1) Academic burnout}

Academic burnout was measured using the Maslach Burnout Inventory-Student Survey [12] and translated and validated by Lee and Lee [13] for medical students in Korea. This survey required subjects to reflect on three factors-emotional exhaustion (five questions), cynicism (four questions), and academic efficacy (reversely rated, six questions)-measured on a 7-point Likert scale. Each item was scales by the 7-point Likert scaling system and higher points were interpreted as high likelihood of academic burnout. The scale yielded a Cronbach $\alpha$ of 0.702 in the current study.

\section{2) Empathy among medical students}

To examine empathy, Korean version of the Jefferson Scale of Empathy-S was used. The original scale [14] was translated by Kim et al. [15] into Korean for measuring medical students' empathy skills. The scale was made up of 18 items related to two subscales, namely, psychology (16 questions) and perception (two questions). The 7point Likert scale system was employed and higher scores were considered to reflect higher empathy. The scale's Cronbach $\alpha$ was 0.656 in the current study.

\section{3) Sense of calling}

In order to measure sense of calling, Korean Vocation Calling Questionnaire (CVQ-K) was used. CVQ-K was developed based on the Calling and Vocation Questionnaire of Dik et al. [16] and translated and validated by Shim and Yoo [17]. The scale was comprised of five subscales - work value (five questions), goal orientation through work (five questions), motivation for contribution and devotion (five questions), sense of calling (five questions), and selfless behavior (five questions) - that were assessed on a 7-point Likert scale. The score scale ranged from "strongly disagree" (1 point) to "strongly agree" (7 points) as in the Likert scale, and higher points indicated higher degrees of calling. A Cronbach $\alpha$ of 0.947 was obtained for the scale in the current study.

\section{Data analysis}

\section{1) Quantitative data analysis}

A correlation analysis was conducted and frequencies and descriptive statistics obtained. In addition, hierarchical multiple regression analysis based on mediatingeffect analysis method of Baron and Kenny [18], as well as the Sobel test, were conducted to determine calling's mediating effect on the relationship between academic burnout and empathy. The collected data were analyzed using SPSS ver. 12.0 (SPSS Inc., Chicago, USA).

\section{2) Qualitative data analysis}

The time taken for the FGI was 2 hours, and the whole interview was recorded on audio and then transcribed. The primary analysis consisted of assigning a code to the important portions of the interview and categorized on the basis of the topic. The data was then recategorized by focusing on the basis of the interpretation followed by representative reaction with respect to the category and described in the results section together with the quantitative data.

\section{Results}

\section{Descriptive statistics for academic burnout, calling and empathy}

A descriptive statistics analysis was conducted to examine the means and standard deviations (SDs) of the academic burnout, sense of calling, and empathy variables. The results in Table 2 show that students' perceived average academic burnout was measured at $4.64 \pm 0.66$, psychological burnout was measured at 
$5.25 \pm 1.07$, sense of incompetence was measured at $4.52 \pm 0.89$, and cynicism was measured at $4.16 \pm 1.02$. The average scores for vocation were measured at $3.48 \pm 0.49$, work value was measured at $3.53 \pm 0.56$, goal orientation through work was measured at $3.66 \pm 0.54$, a sense of calling was measured at $3.21 \pm 0.73$, motive for contribution and devotion was measured at $3.31 \pm 0.65$, and selfless behavior was measured at $3.71 \pm 0.51$. Finally, the medical students' mean score on empathic abilities was measured at $4.36 \pm 0.37$.

\begin{tabular}{lc}
\hline $\begin{array}{l}\text { Table 2. Descriptive Statistics for Academic Burnout, Calling, and } \\
\text { Empathy }\end{array}$ \\
\hline \multicolumn{1}{c}{ Variable } & Mean \pm SD \\
\hline 1. Academic burnout & $4.64 \pm 0.66$ \\
1-1. Emotional exhaustion & $5.25 \pm 1.07$ \\
1-2. Sense of incompetence & $4.52 \pm 0.89$ \\
1-3. Cynicism & $4.16 \pm 1.03$ \\
2. Calling & $3.48 \pm 0.49$ \\
2-1. Work value & $3.53 \pm 0.57$ \\
2-2. Goal orientation through work & $3.66 \pm 0.55$ \\
2-3. Vocation & $3.21 \pm 0.73$ \\
2-4. Motive for contribution and devotion & $3.31 \pm 0.65$ \\
2-5. Selfless behavior & $3.71 \pm 0.51$ \\
3. Empathy & $4.36 \pm 0.37$ \\
\hline
\end{tabular}

SD: Standard deviation.

\section{Correlations between academic burnout, sense of calling, and empathy}

The results of the correlation analyses for variables are presented in Table 3. An analysis of the correlations between academic burnout, sense of calling, and empathy found a significant, negative correlation between academic burnout and sense of calling $(r=-0.291, p<0.01)$. A significant, negative correlation between academic burnout and empathy was also observed $(\mathrm{r}=-0.198, \mathrm{p}<0.05)$. Moreover, a significant, positive correlation was found between sense of calling and empathy $(r=0.316, p<0.01)$. Empathy, a dependent variable, had a significant, negative correlation with psychological burnout $(r=-0.292$, $\mathrm{p}<0.01)$ and cynicism $(\mathrm{r}=-0.238, \mathrm{p}<0.01)$, and a significant, positive correlation with a sense of incompetence $(r=0.184, p<0.05)$. Furthermore, empathy was shown to have a significant, positive correlation with all of the subscales of sense of calling: work value $(r=0.267, \mathrm{p}<$ 0.01), goal orientation through work $(\mathrm{r}=0.223, \mathrm{p}<0.05)$, vocation $(r=0.368, p<0.01)$, motive for contribution and devotion $(r=0.372, p<0.01)$, and selfless behavior $(r=$ $0.212, \mathrm{p}<0.05)$.

Table 3. Correlation among the Variables

\begin{tabular}{|c|c|c|c|c|c|c|c|c|c|c|c|}
\hline Variable & 1 & $1-1$ & $1-2$ & $1-3$ & 2 & $2-1$ & $2-2$ & $2-3$ & $2-4$ & $2-5$ & 3 \\
\hline 1 & 1 & & & & & & & & & & \\
\hline $1-1$ & $0.792^{* *}$ & 1 & & & & & & & & & \\
\hline $1-2$ & $0.368^{* *}$ & -0.086 & 1 & & & & & & & & \\
\hline $1-3$ & $0.791^{* *}$ & $0.565^{* *}$ & -0.066 & 1 & & & & & & & \\
\hline 2 & $-0.291^{* *}$ & $-0.365^{* *}$ & $0.223^{*}$ & $-0.377^{* *}$ & 1 & & & & & & \\
\hline $2-1$ & $-0.0306^{* *}$ & $-0.324^{* *}$ & $0.276^{* *}$ & $-0.494^{* *}$ & $0.815^{* *}$ & 1 & & & & & \\
\hline $2-2$ & $-0.263^{* *}$ & $-0.256^{* *}$ & 0.115 & $-0.342^{* *}$ & $0.843^{* *}$ & $0.658 * *$ & 1 & & & & \\
\hline $2-3$ & -0.164 & $-0.307^{* *}$ & $0.300^{* *}$ & $-0.257^{* *}$ & $0.823^{* *}$ & $0.600^{* *}$ & $0.590^{* *}$ & 1 & & & \\
\hline $2-4$ & $-0.240^{* *}$ & $-0.288^{* *}$ & 0.053 & $-0.212^{*}$ & $0.816^{* *}$ & $0.551^{* *}$ & $0.549^{* *}$ & $0.587^{* *}$ & 1 & & \\
\hline $2-5$ & $-0.249^{* *}$ & $-0.328^{* *}$ & 0.156 & $-0.275^{* *}$ & $0.822^{* *}$ & $0.578^{* *}$ & $0.742^{* *}$ & $0.514^{* *}$ & $0.636^{* *}$ & 1 & \\
\hline 3 & $-0.198^{*}$ & $-0.292^{* *}$ & $0.184^{*}$ & $-0.238^{* *}$ & $0.361^{* *}$ & $0.267^{* *}$ & $0.223^{*}$ & $0.368^{* *}$ & $0.372^{* *}$ & $0.212^{*}$ & 1 \\
\hline
\end{tabular}

1: Academic burnout, 1-1: Emotional exhaustion, 1-2: Sense of incompetence, 1-3: Cynicism, 2: Calling, 2-1: Work value, 2-2: Goal orientation through work, 2-3: Vocation, 2-4: Motivation of contribution and devotion, 2-5: Selfless behavior, 3: Empathy.

${ }^{*} \mathrm{p}<0.05,{ }^{*} \mathrm{p}<0.01$. 


\section{Academic burnout}

The education system whereby a medical student remains in the same class and repeats another year in a small class of 40 is a heartless system that prohibits development of a sympathetic attitude. Rather than expressing a sympathetic attitude towards my fellow students, the first thing that comes to mind is how to be better academically compared to my classmates (Third year female medical student).

On entering medical school I was very impressed with the acivements and chronicles of famous doctors on television documentary programs and by reading many books. I promised to myself that I too would become a good physician. But honestly spaeking, these previous thought are no longer with me during my studies. My life at the present is on a day to day basis or just trudging along from week to week. The really meaningful studies that I would like to do has been replaced by memorizing past exam questions, and thoughts about not faling behind my students friends in this flunking system (Second year male medical student).

\section{Sense of calling}

A doctor is a person who directly and indirectly treats people's lives. If I was to be person who affects the lives of other people, I would have to successfully complete my education studies. If I was to accomplish these arduous medical school studies, then I would become succeed in becoming a respected doctor (Second year female medical student).

I do not think that becoming a doctor is an accomplishment that one can achieve alone. My attitude towards my friends and fellow students should be the same as those towards a patient. The showing of my consideration towards others is the same as the starting of my studies (First year female medical student).

\section{Mediating effect of calling on the relationship between academic burnout and empathy}

To investigate whether a sense of calling mediates the relationship between academic burnout and empathy, the study utilized the three-step procedure suggested by Baron and Kenny [18]. Multiple regression analysis was performed to evaluate the effect of academic burnout and calling. The results are shown in Table 4. academic burnout and calling could explain 17\% ( $\mathrm{F}=13.819$, $\mathrm{p}<0.01$ ) for empathy. As shown in Table 5, academic burnout and empathy explained each other in a significant manner $(\beta=-0.111, p<0.05)$, while academic burnout significantly explained the mediating variable, sense of calling $(\beta=-0.218, p<0.001)$.

Moreover, when academic burnout and sense of calling were simultaneously salient, academic burnout's effect on empathy was no longer significant. Academic burnout and sense of calling explained $13.9 \%$ of empathy. This implies that sense of calling completely mediates the

Table 4. Multiple Regression Analysis of Academic Burnout and Calling on Empathy

\begin{tabular}{|c|c|c|c|c|}
\hline \multirow{2}{*}{ Independent variable } & \multicolumn{2}{|c|}{ Unstandardized coefficients } & \multirow{2}{*}{$\begin{array}{c}\text { Standardized coefficients } \\
\beta\end{array}$} & \multirow{2}{*}{ t-value } \\
\hline & $\beta$ & Standard error & & \\
\hline Academic burnout & -0.011 & 0.050 & -0.017 & -0.213 \\
\hline Calling & 0.309 & 0.061 & 0.408 & $5.083^{* * *}$ \\
\hline \multicolumn{5}{|c|}{$R^{2}=0.170$, adjusted $R^{2}=0.158, F-v a l u e=13.819^{* * *}$} \\
\hline
\end{tabular}

${ }^{* * *} p<0.001$. 
Table 5. Hierarchical Multiple Analysis of the Mediating Effect of Calling

\begin{tabular}{|c|c|c|c|c|c|c|c|c|}
\hline \multirow{2}{*}{$\begin{array}{c}\text { Dependent } \\
\text { variable }\end{array}$} & \multirow{2}{*}{$\begin{array}{l}\text { Independent } \\
\text { variable }\end{array}$} & \multicolumn{2}{|c|}{ Unstandardized coefficients } & \multirow{2}{*}{$\begin{array}{c}\begin{array}{c}\text { Standardized } \\
\text { coefficients }\end{array} \\
\beta\end{array}$} & \multirow{2}{*}{ t-value } & \multirow{2}{*}{$\mathrm{R}^{2}$ (adjusted $\mathrm{R}^{2}$ ) } & \multirow{2}{*}{$\Delta^{2}$} & \multirow{2}{*}{ F-value } \\
\hline & & $\beta$ & Standard error & & & & & \\
\hline Calling & $\begin{array}{l}\text { Academic } \\
\text { burnout }\end{array}$ & -0.218 & 0.064 & -0.291 & $-3.399 * * *$ & $0.085(0.077)$ & & $11.553^{* * *}$ \\
\hline \multirow[t]{3}{*}{ Empathy } & $\begin{array}{l}\text { Academic } \\
\text { burnout }\end{array}$ & -0.111 & 0.049 & -0.198 & $-2.254^{*}$ & $0.039(0.031)$ & & $5.074^{*}$ \\
\hline & $\begin{array}{l}\text { Academic } \\
\text { burnout }\end{array}$ & -0.057 & 0.049 & -0.101 & -1.162 & $0.139(0.126)$ & 0.100 & $10.049 * * *$ \\
\hline & Calling & 0.249 & 0.065 & 0.331 & $3.805^{* * *}$ & & & \\
\hline
\end{tabular}

${ }^{*} p<0.05,{ }^{* * *} p<0.001$.

relationship between academic burnout and empathy. The Sobel test was carried out to verify the statistical significance of the mediating effect. The results confirmed that sense of calling had a statistically significant mediating effect on the relationship between academic burnout and empathy $(\mathrm{Z}=-0.254, \mathrm{p}<0.05)$.

\section{Mediating effect of calling}

I wanted to be person who could help others, and becoming a doctor was one of those ways. I received an oppotunity to achieve this goal when I completed my high school exams and unversity entrance exams. I became someone who could help other people who were ill or sick. The process of becoming a doctor is arduous and difficult but I am sure that I will complete this task. Since this is a mountain that needs to be overcome I will grit my teeth and achieve my goal (Second year male medical student).

To become a qualified person and doctor who may influence the life and death of other people, I am sure that the great deal of amount of study placed before me would be necessry. I transferred to the medical school because I wanted to experience a life that includes talking with patients and that is fruitful with mening. I hope that I will be a successful and contributing person in society and dedicate myself to earning the respect of those society members (First year male medical student).

\section{Discussion}

There are many studies done in other countries about the relationships among medical student burnout, empathy, work value, and professionalism [19-22]. This study was aimed at examining the relationship between medical students' academic burnout and their empathy, and determining whether a sense of calling serves as a mediating variable in the relationship. The results and implications thereof are presented below.

First, empathy was found to negatively correlate with academic burnout $(r=-0.198)$, while positively correlating with sense of calling $(\mathrm{r}=0.361)$ in a significant manner. This indicates that medical students with less academic burnout and a higher calling are more likely to have greater empathy. This result is compatible with that found in a study by Brazeau et al. [23], which found a negative correlation between empathy and the subscales of medical psychological burnout. The results further match those of Rasinski et al. [7], wherein ordinary employees' sense of calling and empathy were found to have a significant positive correlation with each other. 
The negative relationships between sense of calling and academic burnout $(r=-0.291)$ can be considered in line with Baltes and Baltes's [24] claim, according to which, stresses arising in the process of pursuing a difficult goal can be reduced by attempting to achievea greater objective. Moreover, the finding that vocation has a more positive association with empathy than with academic burnout suggests that sense of calling could be an effective indicator of medical students' empathy.

Next, medical students' perceived academic burnout had a significant, negative effect on their empathy $(\beta=$ $-0.111, p<0.05$ ), meaning that the more burnt out they were in relation to their studies, the less empathetic they were. This result corresponds with that in another study, in which medical students with more severe psychological burnout had less empathy [25]. This also suggests that the educational system in medical schools, which could place students under extreme stress through the drop-out systemfrequent testing, and large amounts of information to be covered, might prevent students from nurturing an empathetic attitude. As such, there is a need for an educational program wherein students could obtain both the necessary knowledge and attitudes to become a balanced and empathetic doctor.

Finally, hierarchical multiple regression analysis, which was used to determine whether sense of calling mediates the relationship between academic burnout and empathy, showed that sense of calling fully mediates this relationship. This indicates that academic burnout might influence one's empathic skills through sense of calling. This means that, although medical students who are academically burnt out are less likely to be empathetic, a strong sense of calling could facilitate greater empathic capacity among them. This corresponds with some previous research [16], which found that sense of calling had a mediating effect when burnout negatively influenced job-related variables.
This study has some limitations. It is apparent that one of the drawbacks of this study is that only a specific group of students in a single educational institution were included in the present study. Another disadvantage is that a greater number of variables that may affect empathetic attitude should have been included and analyzed for improved statistical performance. As such, further research should entail the design of study models including various internal and external variables related to individuals' empathy. This would enable the examination of structural relationships between variables that affect medical students' empathy. Such efforts would enable the determination of theoretical grounds for a concrete and practical intervention aimed at improving medical students' empathy.

In conclusion, this present study verified the effects of academic burnout and sense of calling on medical students' empathic skills with mixing quantitative and qualitative data analyses. we found the mediating effect of sense of calling on the relationship between academic burnout and medical students' empathy. We identified the importance of calling, an individual's internal psychological variable, in advancing medical students' empathy. By discovering sense of calling's mediating effect on the relationship between medical students' academic burnout and empathy, this study proved that sense of calling, plays an important role in enhancing students' empathy.

\section{ORCID:}

Su Jin Chae: https://orcid.org/0000-0003-3060-8933;

So Mi Jeong: https://orcid.org/0000-0002-6984-9753;

Yoon-Sok Chung: https://orcid.org/0000-0003-0179-4386

Acknowledgements: None.

Funding: The authors received no financial support for the research, authorship, and/or publication of this article. 
Conflicts of interest: The authors declared no potential conflicts of interest with respect to the research, authorship, and/or publication of this article.

Author contributions: All authors contributed substantially to the conception and design of the study. SJC and SMJ wrote the paper. SJC revised the paper to reviewers' comment and conducted FGI. SMJ collected and analyzed quantitative data. YSC commented on the original article.

\section{References}

1. Yoo HH, Lee JK, Kim A. Perceptual comparison of the "good doctor" image between faculty and students in medical school. Korean J Med Educ. 2015;27(4): 291-300.

2. Halpern J. What is clinical empathy? J Gen Intern Med. 2003;18(8):670-674.

3. Shanafelt TD, West C, Zhao X, et al. Relationship between increased personal well-being and enhanced empathy among internal medicine residents. J Gen Intern Med. 2005;20(7):559-564.

4. West CP, Huschka MM, Novotny PJ, et al. Association of perceived medical errors with resident distress and empathy: a prospective longitudinal study. JAMA. 2006;296(9):1071-1078.

5. Hojat M, Mangione S, Nasca TJ, et al. An empirical study of decline in empathy in medical school. Med Educ. 2004;38(9):934-941.

6. Duffy RD, Dik BJ, Steger MF. Calling and work-related outcomes: career commitment as a mediator. J Vocat Behav. 2011;78(2):210-218.

7. Rasinski KA, Lawrence RE, Yoon JD, Curlin FA. A sense of calling and primary care physicians' satisfaction in treating smoking, alcoholism, and obesity. Arch Intern Med. 2012;172(18):1423-1424.
8. Peterson C, Park N, Hall N, Seligman ME. Zest and work. J Organ Behav. 2009;30(2):161-172.

9. Martin P, Kelly N, Kahana B, et al. Defining successful aging: a tangible or elusive concept? Gerontologist. 2015;55(1):14-25.

10. Zhang C, Hirschi A, Herrmann A, Wei J, Zhang J. Self-directed career attitude as predictor of career and life satisfaction in Chinese employees: calling as mediator and job insecurity as moderator. Career Dev Int. 2015;20(7):703-716.

11. Yoon JD, Daley BM, Curlin FA. The association between a sense of calling and physician well-being: a national study of primary care physicians and psychiatrists. Acad Psychiatry. 2017;41(2):167-173.

12. Schaufeli WB, Salanova M, González-Romá V, Bakker $\mathrm{AB}$. The measurement of engagement and burnout: a two sample confirmatory factor analytic approach. J Happiness Stud. 2002;3(1):71-92.

13. Lee SH, Lee DY. Validation of the MBI-SS scales-based on medical school students. Asian J Educ. 2013;14(14): 165-187.

14. Hojat M, Mangione S, Nasca TJ, et al. The Jefferson Scale of physician empathy: development and preliminary psychometric data. Educ Psychol Meas. 2001;61(2): 349-365.

15. Kim IS, Kim YH, Chang HI. An investigation on reliability and validity of the Korean medical students' empathy rating scale. Korean J Psychopathol. 2004; 13(13):9-15.

16. Dik BJ, Duffy RD, Eldridge BM. Calling and vocation in career counseling: recommendations for promoting meaningful work. Prof Psychol Res Pract. 2009;40(6): 625.

17. Shim Y, Yoo SK. Development and validation of the Korean version of the calling and vocation questionnaire (CVQ-K). Korean J Couns Psychother. 2012;24(4):847872. 
18. Baron RM, Kenny DA. The moderator-mediator variable distinction in social psychological research: conceptual, strategic, and statistical considerations. J Pers Soc Psychol. 1986;51(6):1173-1182.

19. Duffy RD, Allan BA, Bott EM. Calling and life satisfaction among undergraduate students: investigating mediators and moderators. J Happiness Stud. 2012; 13(3):469-479.

20. Passalacqua SA, Segrin C. The effect of resident physician stress, burnout, and empathy on patientcentered communication during the long-call shift. Health Commun. 2012;27(5):449-456.

21. Zenasni F, Boujut E, Woerner A, Sultan S. Burnout and empathy in primary care: three hypotheses. Br J Gen Pract. 2012;62(600):346-347.
22. Ren GS, Min JT, Ping YS, et al. Complex and novel determinants of empathy change in medical students. Korean J Med Educ. 2016;28(1):67-78.

23. Brazeau CM, Schroeder R, Rovi S, Boyd L. Relationships between medical student burnout, empathy, and professionalism climate. Acad Med. 2010;85(10 Suppl): S33-S36.

24. Baltes PB, Baltes MM. Psychological perspectives on successful aging: the model of selective optimization with compensation. Success Aging Perspect Behav Sci. 1990; I(1):1-34.

25. Paro HB, Silveira PS, Perotta B, et al. Empathy among medical students: is there a relation with quality of life and burnout? PLoS One. 2014;9(4):e94133. 